\title{
The Definition of Pharmaceutical Professional Students' Cultural Capital and Its Measure Index Construction
}

\author{
Yan Huang ${ }^{1}$, Kunling Weng ${ }^{2}$, Qin Fang ${ }^{3} \&$ Boyang $\mathrm{Yu}^{1}$ \\ ${ }^{1}$ School of International Pharmaceutical Business, China Pharmaceutical University, Nanjing, China \\ ${ }^{2}$ Co-first Author, School of Science, China Pharmaceutical University, Nanjing, China \\ ${ }^{3}$ School of Science, China Pharmaceutical University, Nanjing, China \\ Correspondence: Boyang Yu, School of International Pharmaceutical Business, China Pharmaceutical University, \\ Nanjing 211198, China. E-mail: boyangyucpu@163.com
}

$\begin{array}{lc}\text { Received: April 2, } 2017 & \text { Accepted: April 19,2017 Online Published: April 27, } 2017 \\ \text { doi:10.5539/par.v6n1p40 } & \text { URL: http://dx.doi.org/10.5539/par.v6n1p40 }\end{array}$

\begin{abstract}
On the basis of learning form many scholars' research achievements, this paper goes into the distinctive group of pharmaceutical professional students. And combined with the requirements of job market for college students' cultural capital, this paper comprehensively analyzes pharmaceutical professional students' cultural capital meanwhile, and puts forward the definition of pharmaceutical professional students' cultural capital for the first time. Through the way of knowledge-transference, environment influence and their own practice, the pharmaceutical professional students translate the human outstanding culture achievements into their character, values and professional spirit, turning into their relatively stable inner quality and behavioral pattern in the process of pharmaceutical education. It is mainly shown as kindheartedness spirit, scientific spirit and craftsman spirit. So far, a unified standard of measuring college students' cultural capital has not formed. In this paper, through literature review and combined with the research purpose, the measurement for pharmaceutical professional students' cultural capital is finally implemented into the measurement for the main connotation of cultural capital, which is kindheartedness spirit, scientific spirit and craftsman spirit. Through the questionnaire survey data, exploratory factor analysis and confirmatory factor analysis are processed, and finally the measurement index system of pharmaceutical professional students' cultural capital is built, which passes the testing of validity and reliability.
\end{abstract}

Keywords: pharmacy specialty, undergraduate, cultural capital, connotation, measurement index

\section{Introduction}

University culture is gradually formed with the formation of university, slowly accumulates with the development of university, is produced in the process of long-term interaction between teachers and students, and is capital manifesting the social value and status of university. The university culture capital can continue to influence students subtly, that is more influential than the formal school education.

Some scholars pointed out that as a kind of cultural atmosphere permeated in the campus, the mental factor, belief factor, tradition and morality implied in university culture affect students' ideology, moral system, psychological personality and behavior habit directly or indirectly by the way of specification, edification, enlightenment and management.

School is the place of transfering human culture knowledge, students acquire knowledge and skills here. The function of cultural capital is to create a special cultural atmosphere, which can make the students placed themselves among it more actively acquire knowledge and skills. In such an environment, college students can voluntarily accept the influence of university culture on his thoughts, behavior, and mental quality, so as to realize the social role transformation. In this process, the university culture can help students to set up correct outlook of world, life and values, and establish the correct standard of judging right and wrong.

\section{The Definition of Pharmaceutical Professional Students' Cultural Capital}

Cultural capital was put forward first by the French famous contemporary sociologist Pierre Bourdieu in his famous paper "The forms of capital" (Bourdieu, 1989). He points out that the cultural capital is a value form 
which is regarded as the orthodox cultural interest, consumption patterns, cultural ability, education qualifications and so on, indicating the actor's the social identity. He put the cultural capital as a kind of social structure, one capital form in common sense, drawing level with economic capital and social capital. In 1985, DiMaggio Paul, a professor at the university of Yale and John W. Mohr published a paper "cultural capital, education achievement and marriage choice". They linked cultural capital with school performance, and found that cultural capital affected education achievement, college admission, graduation rates, graduate student enrollment between girls and boys, through quantitative and qualitative methods. This new research angle caused many scholars' deep research on college students' cultural capital.

Domestic scholars Wang Weiping, Ye Zhong (2015) divided college students' cultural capital into three categories in an analysis of the support of cultural capital for college graduates' employment: The attitude, emotion, temperament, internalizing in college students' personal body, which are approved and lasted by themselves, rapid developing cultural industries, normative labour market and specific education qualification authentication mechanism. At present, the research literature about college students' cultural capital is few, most of which are conceptual, description, empirical and suggested qualitative researches, while quantitative research of cultural capital is almost blank.

Each university has its own cultural capital, it is a characteristic capital which is different from other university. So pharmaceutical colleges have their own connotation of cultural capital, being different from other colleges and universities. And the connotation truly reflects differences between the pharmaceutical professional students and other students. The connotation of pharmacy college and universities students' cultural capital should include their values, professional spirit, professional ethics, and character, etc.

(1) Pharmacy as a science is closely related to human health, first of all, it is a natural science. As a result, it must be with properties of natural science. Firstly, a pharmaceutical professional student should have scientific method of thinking and ideas. Scientific thinking is the basis of the set up scientific world view, it refers to the philosophy and methodology. The importance of scientific thinking mainly reflects in that scientific thinking can guide the researchers to find the movement law of things inside and the inner link between things, and then produce unique theory and method and use them in their field of study, this is one of the basic process of creative activities. Creative thinking is the basis and premise of all innovation activities, including divergent thinking, concession thinking, questioning thinking, non-attribution thinking and flexible thinking, eventually forming the students' innovation consciousness and creative thinking to lay a solid foundation for innovation activities.

Meanwhile, drug research and development is an exploratory research process. In the gradual process, pharmaceutical engineering students should take reasonable suspicion and adhere to the rational thinking to adjust and change the drug research and development process, continuously overturn and clarify, In the process of constant practice, thinking, innovation and verification, the pharmacy class students' scientific research spirit is trained. Therefore, the experts think that scientific research spirit of seeking truth from facts, exploration of questioning the difficult, innovation, and verification should be as an important part of the connotation of a pharmaceutical professional student's capital cultural.

(2) Pharmacy not only is a pure natural science, but also has a profound and obvious humanistic spirit. First of all, pharmaceutical engineering students' humanistic spirit shows the great kindheartedness spirit. Kindheartedness spirit is the inner soul of the Chinese traditional culture, it should be centered on "benevolence" to care patients and pay attention to "love". We should treat patients with the psychology of mercy and purdue beings concept. Many title of old Chinese medicine tong has a unique meaning, mostly reflects the artistic conception of "aiding the world and saving the people", some Zuxun of hundred years old and famous shop or enterprise emphasize the cultural values of "Kindheartedness". Such as, "TongRenTang" means "with kindheartedness, saving their health". Darren Hall emphasizes "Reach the world longevity, benevolent love can spring back to".

The pharmaceutical professional students understanding of drugs, medicines and pharmaceutical can't just stay on the level of knowledge and technology, but should also deepen the level of society consciousness. It is a long process to cultivate pharmaceutical engineering students' humane spirit, the sense of responsibility and mission, which needs subtle education and edification.

(3) A pharmaceutical professional students also should have the spirit of craftsman. The spirit of craftsman refers to the craftsman's finely crafted, striving for perfection spiritual idea to their products. Its core is a kind of spirit of insistence to work and striving for perfection to the products. This study thinks that the connotation of craftsman spirit should include the following aspects: Striving for perfection, improving products repeatedly from $99 \%$ to $99.99 \%$, being strict in their work, adhering to improve product quality and service consciousness 
constantly, professional dedication. So to speak, the spirit of craftsman is a kind of professionalism. And this kind of craftsman spirit is a professional spirit which a pharmaceutical professional student should have.

Medicines are special commodities to prevent and treat diseases, heal the wounded and rescue the dying. It will cure the sickness and save the patient if the medicines are used properly. Otherwise, it will delay the treatment light or affect the life badly, the consequence is unimaginable. Therefore, pharmaceutical professional students must have the professionalism of keeping improving, concentration, being strict and adhereing to. We should put the craftsman spirit to every detail, running through the whole part from $R \& D$ to regulation of drugs. Only in this way can we ensure that each drug is safe and effective. This is every medical person's special social responsibility.

In conclusion, on the basis of referring many scholars' research achievements, this paper analyzes deeply the pharmaceutical professional students, a distinctive group, and comprehensively analyzes the cultural capital of pharmaceutical students, puts forward the definition of pharmaceutical engineering students cultural capital for the first time.

Through the way such as knowledge-transference, environment edification and their own practice, pharmaceutical professional students melt the human outstanding culture achievements into the character, values and the professional spirit in the process of pharmaceutical education, to become the inner quality of pharmaceutical engineering students and relatively stable behaviors, mainly shown as kindheartedness spirit, scientific spirit and craftsman spirit.

Kindheartedness spirit is fundamental to the cultural capital of a pharmaceutical professional students. Drug is an important mean to maintain human health, whether a pharmaceutical professional student can make their due contribution to social development depends on not only their high scientific and cultural quality, but also noble moral sentiment and strong social sense of responsibility.

Scientific spirit is the core of a pharmaceutical professional students' cultural capital. The demand for high level medicine experts, researchers, pharmacy education talented person is growing for the future society, this also put forward higher request to them. A pharmaceutical professional student should not only master professional knowledge, but also have the ability of applying knowledge and creating knowledge.

Craftsman spirit is the main part of the cultural capital. Pharmacy talents shoulder the task of ensuring human health, this requires a pharmaceutical professional student uphold professional ethic of keeping improving, perseverance, pursue excellence and perfection.

\section{The Construction of Measurement Index System of Pharmaceutical Professional Students' Cultural Capital}

So far, a unified measure standard has not formed for the college students' cultural capital. Measurement is a process to judge fact and has strong objectivity, it is a process of assignment and quantitative analysis. In this paper, the measure for pharmaceutical professional students' cultural capital eventually is implemented to measure the main connotation of cultural capital, including kindheartedness spirit, scientific spirit, and craftsman spirit.

The concept of spirit is relatively abstract, it cannot be expressed clearly both in study and practice, so it need to be further decomposed. In general, for the measure of spirit, we can externalize the spirit to behaviors and attitudes on the basis of understanding the connotation of spirit. The method of deconstruction and construction is adopted to explore the dimensions of kindheartedness spirit, scientific spirit and craftsman spirit, in order to facilitate people to analyze and guide practice deeply. Before analyzing indicators, the meaning of spirit and the measurement indicators should be clarified.

\subsection{The Measurement Index Refining of Pharmaceutical Professional Students' Cultural Capital}

3.1.1 Kindheartedness Is the Essence of Pharmaceutical Professional Students' Cultural Capital, and It Is the Concentrated Reflection of Values and Ethics of Pharmaceutical Professional Students

Kindheartedness is the core of Confucian interpersonal relationship theory. Benevolence contains two meanings, 1) Firstly, benevolence is a kind of blood love of family, refers to kinship among parents and brothers. 2) "The benevolent loves others" refers to relationships outside of the blood. Benevolence is not only the basic rule people deal with the relationship among blood relatives, but also the principles to deal with all social relationships.

Modern scholars also define the kindheartedness spirit. In his master's thesis, Yunfeng Xu (2007) divided kindheartedness into love relatives and love people. Rongjuan Bao (2009) argued that the thought of 
kindheartedness mainly reflected in three aspects: personal moral cultivation, family relations cultivation and social morality cultivation. Ji $\mathrm{Hu} \& \mathrm{Yu}$ Liao (2009) argued that three aspects, strengthening family education, creating a good social atmosphere, colleges and universities pay attention to guide, should be carried out to cultivate college students' kindheartedness spirit.

This paper argues that kindheartedness spirit for pharmaceutical professional students is that they can understand the position, feelings and thoughts of others, stand in the perspective of others to deal with problems in the process of interpersonal communication. Specifically, it is to learn to respect, pity and help others. Only the students respect for others, they can be in harmony with people and communicate with others. This is both one of human behavior methods and a reflection of kindheartedness spirit. It is not only a noble thoughts and feelings, but also the manifestation of kindheartedness spirit to pity others. If compassion reflects kindheartedness spirit mainly in the thoughts and feelings, helping others shows tkindheartedness spirit from action more.

Through literature review and combined with the research purpose, this paper assesses the kindheartedness of pharmaceutical professional students' cultural capital quantitatively from the following two aspects, moral principles and environment support. Moral principle is behaviour standard when a college student handles the relationship between human and society. Environment support is that the external environment of college students can help them cultivate kindheartedness spirit.

3.1.2 Scientific Spirit Is the Core of Pharmaceutical Professional Students' Cultural Capital, and It Is an Important Content of Pharmaceutical Professional Students' Personal Quality

Scientific spirit is the common belief, value standard and behavioral norms formed in the long-term practice, which can be used to measure the students' scientific research and innovation ability. For example, Wei Lu (2004) argued that the college students' scientific spirit should be measured separately from the subjective and objective factors. Subjective factors include exploring and questioning ability, curiosity and desire for knowledge, seeking truth from facts. Objective factors include academic environment, practice opportunity and evaluation system. Xianfei Yi (2005) argued that indicators of college students' scientific spirit included seeking truth from facts, innovation ability, sticking to the truth, the pursuit of truth, professional academic performance. Xianglin Zhang (2010) argued that the measurable indicators of scientific and technological person's scientific spirit included having a strong consciousness of innovation and research interest, being active to the scientific research work, daring to try challenging topic or direction, academic rigor, being not impetuous or eager for quick success and instant benefits, not blindly following for authority, and doing scientific research with great concentration, resisting external disturbance and temptation.

This study argues that scientific spirit mainly refers to truth-seeking spirit, rational criticism spirit, innovation spirit and the team cooperation spirit in the connotation of pharmaceutical professional students' cultural capital.

Truth-seeking spirit is the spirit of seeking truth from facts as we know. Observation and experiment is the basic method of scientific research, the objective knowledge is the result of scientific research, the pursuit of objectivity is the basic norms of scientific research. Rational criticism spirit is to put forward questions on the basis of the realistic and rational principles, do not blindly follow and firmly believe their own judgment. Innovation spirit is the inevitable requirement of era and society for science. In a nutshell, innovative people generally reflected in that they can find what others can't see and think. In the process of scientific research, cooperation spirit emphasizes the need for through cooperation and exchanges to improve. With the gradually thorough progress of scientific research, the solution of many problems requires interdisciplinary knowledge, no individual can complete all tasks of scientific development.

Through literature review and combined with the aim of this study, this thesis divides the pharmaceutical professional students' scientific spirit into the following three categories: scientific research ability, system guarantee and academic environment. Scientific research ability includes the scientific literacy such as college students' innovation ability, seeking knowledge desire, critical thinking. Institutional guarantee is to guarantee the scientific exploration of college students from the system aspect. Academic environment is the material basis provided for college students to learn scientific knowledge and skills from schools.

3.1.3 Craftsman Spirit Is the Main Body of Pharmaceutical Professional Students' Cultural Capital, and Is the Manifestation of Students' Professional Spirit

Craftsman spirit refers to the idea that people strive for perfection of their products in the process of working to manifest college students' quality of strict truth-seeking, studying assiduously and being brave in exploitation. Xihu You (2016) thought that the core of college students' craftsman spirit is professional values, therefore, craftsman spirit is measured by professional awareness, professional ethics, professional standards and 
professional evaluation. Liang Zhu (2016) increased the inspection of craftsman spirit on value orientation combined with humanistic spirit, such as governance structures of university, teachers and students ' words and deeds, environment. Besides, it includes moral sentiment, the ideal faith, way of thinking and aesthetic taste. Xiaolu Li (2016) defined craftsman spirit of college students as the unity of professional spirit, professional attitude and cultural literacy.

This study thinks that the craftsman spirit of pharmaceutical professional students includs being passionate in jobs firstly. Concentration and persistence is the manifestation of being passionate in jobs. A pharmaceutical professional student should love their career sensibly, realize the value of their career rationally, treat their career objectively with courtesy caution. Being passionate in jobs is the foundation of craftsman spirit, only the students firm basis, craftsman spirit can burst a dazzling brilliance.

Secondly, craftsman spirit refers to strive for perfection. The craftsman spirit of striving for perfection embodies the pursuit for high quality manufacturing and medicine services of the pharmaceutical professional students, their high responsible spirit for patients, and their never satisfied pursuit for drug quality and efficacy. In this spirit, pharmaceutical professional students with rigorous attitude achieve each job in pharmacy enterprise, and are willing to devote their lives to the inheritance and development of medicine.

Thirdly, craftsman spirit should include striving for truth and innovation. Striving for truth is practical and seeking truth from facts. Innovation means never being satisfied and advancing with the times. Striving for truth is the foundation of innovation, innovation is a reflection of striving for truth. Pharmaceutical professional students should constantly improve pharmaceutical production technology, the quality of medicines, drug efficacy and the efficiency of service, only in this way, can to the level of products and services be improved. Pragmatic pharmaceutical professional students need to be pragmatic, also need to have the romance looking at the sky, strives for truth and innovation is the soul of craftsman spirit.

In this paper, the measure indexes of craftsman spirit are reduced to value orientation and professional quality. Value orientation refers to that a college student regards a certain value as action criterion and the pursuit goal, it is closely combined with college students' outlook on life and values. Professional quality is behavioral norm which need to be abided in the process of college students' professional learning, including professional ethics, professional skills and professional habits.

Through literature review and analysis for the spiritual connotation, spirit can be crystallized into attitudes and behaviors to measure. At the same time, combined with the characteristics of medicine, this study designs theory measurement index system of pharmaceutical professional students' cultural capital shown in the table below.

Table 1. The measurement index system of pharmaceutical professional students' cultural capital

\begin{tabular}{lll}
\hline $\begin{array}{l}\text { Connotation } \\
\text { cultural capital }\end{array}$ & of & Measurement items \\
\hline
\end{tabular}

1. Often take part in various social commonweal activities and youth volunteer activities, such as nursing homes activities and community public welfare activities.

2. Be active to care about them, and give a hand to their life and study, when their

Kindheartedness spirit classmates are sick.

3. Keep in touch with parents actively during the period of university, at least twice a week

4. Take part in social activities actively such as blood and bone marrow donation during the period of university.

1. Often take part in all kinds of scientific research activities organized by schools or teachers during the period of university, such as innovative experiments, open experiments.

Scientific spirit

2. Enrich their science knowledge actively from a variety of sources, such as reading a lot of science and technology books except textbooks, participating in the special science lectures in the university. 
3. Have done in-depth study exploration in university, such as mechanism of drugs, polarity of drugs, and the unique function of medicinal herbs.

4. Often attend science and technology competition activities school with his classmates during the period of university.

1. Be a perfectionist, dealing object especially the preparations of scientific experiment with perfect attitude, strive to the entirety of experiment preparation.

2. Will prepare and operate carefully and look for more effective experimental method, even if the experiment steps are very simple.

Craftsman spirit 3. When the experiment failed, always find the problem actively through various channels, and actively prepare for the next experiment until it succeed.

4. Often take the initiative to give up rest time for the experiment to collect experimental data, prepare experimental materials and optimize experiment method during the university.

\subsection{The Measurement Index Amendment of Pharmaceutical Professional Students' Cultural Capital}

This research adopted the revision of Delphi method, structured questions were used directly to conduct questionnaire survey. In order to facilitate the quantitative research, Likert Scale, the most commonly used quantitative tool in Delphi method was chosen.

Since October 12, 2016, 28 questionnaires were sent out via e-mail. According to the requirement of Delphi method, expert members did not meet and exchange of views. A total of 28 questionnaires were taken back in the first round up to October 15 , the recovery rate was $100 \%$ and the effective rate was also $100 \%$.

The experts advised to add the item reflecting realistic spirit and innovative spirit according to the main content of the scientific spirit in the cultural capital item, and add the item of professional attitude in the craftsman spirit. Observation and experiment is the basic method of scientific research, the objective knowledge is the result of scientific research, and the pursuit of objective is the basic norms of scientific spirit. The experts suggest adding the item recording the results and data faithfully every experiment during university as the indicator measuring the spirit of seeking truth from facts. Innovation is the inevitable requirement of era and society for science. In a nutshell, innovative people generally can find what others can't see and think. The experts suggest adding the item we can often find some details which my classmates can't find, expressing the innovation spirit in the scientific spirit. Value orientation is that a college student regards some value as behavior standard and pursuit goal. The experts suggest adding the item loving medicine and be willing to struggle for the human health of all beings which embodies the value orientation in craftsman spirit.

After the second round new questionnaire was designed, 28 new questionnaires were sent out on November 1 , 2016, 28 questionnaires were taken back up to November 17, the recovery rate was $100 \%$ and the effective rate was also $100 \%$. Through the statistical analysis, the standard deviation of indicators is small, explaining the opinions of the expert group members in the second round of questionnaire is focused, that is to say, the investigate of Delphi method is over. This study chooses indicators of which average is greater than 4 as very important indicators of cultural capital. There are 15 these indicators in total. 
Table 2. The very important indicators of cultural capital

\begin{tabular}{|c|c|c|c|}
\hline $\begin{array}{l}\text { Connotation of } \\
\text { cultural capital }\end{array}$ & Measurement items & $\begin{array}{l}\text { Average } \\
\text { score }\end{array}$ & Standard \\
\hline \multirow{15}{*}{ Cultural capital } & $\begin{array}{l}\text { Often take part in various social commonweal activities and youth } \\
\text { volunteer activities, such as nursing homes activities and } \\
\text { community public welfare activities. }\end{array}$ & 4.54 & 0.86 \\
\hline & $\begin{array}{l}\text { Be active to care about them, and give a hand to their life and study, } \\
\text { when their classmates are sick. }\end{array}$ & 4.36 & 0.85 \\
\hline & $\begin{array}{l}\text { Keep in touch with parents actively during the period of university, } \\
\text { at least twice a week }\end{array}$ & 4.28 & 0.54 \\
\hline & $\begin{array}{l}\text { Take part in social activities actively such as blood and bone } \\
\text { marrow donation during the period of university. }\end{array}$ & 4.81 & 0.22 \\
\hline & $\begin{array}{l}\text { Often take part in all kinds of scientific research activities organized } \\
\text { by schools or teachers during the period of university, such as } \\
\text { innovative experiments, open experiments. }\end{array}$ & 4.48 & 0.56 \\
\hline & $\begin{array}{l}\text { Enrich their science knowledge actively from a variety of sources, } \\
\text { such as reading a lot of science and technology books except } \\
\text { textbooks, participating in the special science lectures in the } \\
\text { university. }\end{array}$ & 4.38 & 0.47 \\
\hline & $\begin{array}{l}\text { Have done in-depth study exploration in university, such as } \\
\text { mechanism of drugs, polarity of drugs, and the unique function of } \\
\text { medicinal herbs. }\end{array}$ & 4.61 & 0.91 \\
\hline & $\begin{array}{l}\text { Often attend science and technology competition activities school } \\
\text { with his classmates during the period of university. }\end{array}$ & 4.37 & 0.54 \\
\hline & $\begin{array}{l}\text { Record the results and data faithfully every experiment during } \\
\text { university }\end{array}$ & 4.45 & 0.75 \\
\hline & Can often find some details which his classmates can't find & 4.72 & 0.83 \\
\hline & $\begin{array}{l}\text { Be a perfectionist, dealing object especially the preparations of } \\
\text { scientific experiment with perfect attitude, strive to the entirety of } \\
\text { experiment preparation. }\end{array}$ & 4.57 & 0.81 \\
\hline & $\begin{array}{l}\text { Will prepare and operate carefully and look for more effective } \\
\text { experimental method, even if the experiment steps are very simple. }\end{array}$ & 4.23 & 0.72 \\
\hline & $\begin{array}{l}\text { When the experiment failed, always find the problem actively } \\
\text { through various channels, and actively prepare for the next } \\
\text { experiment until it succeed. }\end{array}$ & 4.63 & 0.76 \\
\hline & $\begin{array}{l}\text { Often take the initiative to give up rest time for the experiment to } \\
\text { collect experimental data, prepare experimental materials and } \\
\text { optimize experiment method during the university. }\end{array}$ & 4.12 & 0.52 \\
\hline & $\begin{array}{l}\text { love medicine and be willing to struggle for the human health of all } \\
\text { beings. }\end{array}$ & 4.45 & 0.46 \\
\hline
\end{tabular}

By analysis applying SPSS19.0 statistical software, (Cronbach) $\alpha=0.874$. According to the research of DeVilliers, the $\alpha$ coefficient between $0.80-0.90$ is very good. Therefore, this research has very good reliability. 
This study guarantees experts do not communicate each other horizontally in strict accordance with the principles and steps of the Delphi method research. And the expert has deep research in the related theory, or has a wealth of experience in practice. They are able to identify and determine the cultural capital measurement index of pharmaceutical professional students, ensuring the surface validity and content validity of the research.

\subsection{The Pre-test of Pharmaceutical Professional Students' Cultural Capital Measurement Indicators}

In order to test whether the testee can accurately understand the questionnaire item and whether the purpose of the questionnaire is right, this research did pre-test for the questionnaire of pharmaceutical engineering students' cultural capital before the formal research. Pre-test samples are pharmaceutical enterprise employees from 5 companies, Guangzhou Baiyunshan Pharmaceutical holdings Co., Ltd. Baiyunshan Pharmaceutical General Factory, Lianyungang Hengrui Medicine Co., Ltd., HANSON PHARMA, Merck (China) Company, Sinopharm Group Beijing CO., Ltd.. The research taken the network questionnaire, used the questionnaire star survey system to generate online questionnaire, processed cluster sampling via taking post as a unit, sent out 530 questionnaires, and taken back 497 questionnaires including 456 valid questionnaires, the effective rate was $91.75 \%$.

The reliability test. This study used SPSS19 to do reliability test for the cultural capital measurement scale of pharmaceutical professional students in the first examination questionnaire, the results are shown in table 3.

Table 3. Reliability statistics of the first questionnaire scale

\begin{tabular}{ll}
\hline Scale & Cronbachs $\alpha$ based on standardization \\
\hline Cultural capital scale & 0.901 \\
\hline
\end{tabular}

From table 3, the (Cronbach) $\alpha$ of first questionnaire is 0.901 . According to the research of DeVilliers, the $\alpha$ coefficient between $0.80-0.90$ is very good. Therefore, the first questionnaire scale has very good reliability.

Validity test. The first questionnaire in this research is cited and revised on the basis of literature review and expert interview and selects relevant indicators strictly according to the connotation of the indicators at the same time to ensure that the variable measurement has good content validity. As shown in table 4, the factor loading of measurement indicator is between 0.678 to 0.912 , which is greater than the standard value 0.50 , and it is outstanding at the $\mathrm{P}<0.001$ level. The convergent validity of variables is between 0.870 to 0.903 , greater than the standard value 0.70 , so the measurement indicators in this questionnaire have good convergent validity.

Table 4. The analysis result of convergent validity

\begin{tabular}{lccc}
\hline Scale & Items & Factor loading & Convergent validity \\
\hline Cultural capital scale & 15 & $0.724 \sim 0.912$ & 0.903 \\
\hline
\end{tabular}

Item analysis. This study arranges the sum of each item scored by the testees in the test paper according to high to low, the high score group is the top $20 \%$, the low score group is the bottom $20 \%$, and then test the average differences significant of the two groups' score. If the critical ratio (CR) value of the item reaches the significant level $(\mathrm{P}<0.05$ or $\mathrm{P}<0.01)$, it indicates that the item can identify the reaction degree of different testees. Otherwise, it indicates this item can't identify the reaction degree of different testees, and then delete this item. The analysis results of the first questionnaire' items are shown in table 5. 
Table 5. The analysis results of the first questionnaire' items

\begin{tabular}{|c|c|c|c|c|}
\hline $\begin{array}{c}\text { Capital } \\
\text { connotation }\end{array}$ & Measurement items & $\begin{array}{l}\text { High } \\
\text { score } \\
\text { group }\end{array}$ & $\begin{array}{l}\text { Low } \\
\text { score } \\
\text { group }\end{array}$ & P-value \\
\hline \multirow{15}{*}{$\begin{array}{l}\text { Cultural } \\
\text { capital }\end{array}$} & $\begin{array}{l}\text { Often take part in various social commonweal activities and } \\
\text { youth volunteer activities, such as nursing homes activities and } \\
\text { community public welfare activities. }\end{array}$ & 4.74 & 3.68 & 0.004 \\
\hline & $\begin{array}{l}\text { Be active to care about them, and give a hand to their life and } \\
\text { study, when their classmates are sick. }\end{array}$ & 4.64 & 3.65 & 0.004 \\
\hline & $\begin{array}{l}\text { Keep in touch with parents actively during the period of } \\
\text { university, at least twice a week. }\end{array}$ & 4.68 & 3.46 & 0.003 \\
\hline & $\begin{array}{l}\text { Take part in social activities actively such as blood and bone } \\
\text { marrow donation during the period of university. }\end{array}$ & 4.83 & 3.22 & 0.000 \\
\hline & $\begin{array}{l}\text { Often take part in all kinds of scientific research activities } \\
\text { organized by schools or teachers during the period of } \\
\text { university, such as innovative experiments, open experiments. }\end{array}$ & 4.70 & 3.47 & 0.002 \\
\hline & $\begin{array}{l}\text { Enrich their science knowledge actively from a variety of } \\
\text { sources, such as reading a lot of science and technology books } \\
\text { except textbooks, participating in the special science lectures } \\
\text { in the university. }\end{array}$ & 4.78 & 3.43 & 0.003 \\
\hline & $\begin{array}{l}\text { Have done in-depth study exploration in university, such as } \\
\text { mechanism of drugs, polarity of drugs, and the unique function } \\
\text { of medicinal herbs. }\end{array}$ & 4.91 & 3.81 & 0.004 \\
\hline & $\begin{array}{l}\text { Often attend science and technology competition activities } \\
\text { school with his classmates during the period of university. }\end{array}$ & 4.87 & 3.54 & 0.002 \\
\hline & $\begin{array}{l}\text { Record the results and data faithfully every experiment during } \\
\text { university }\end{array}$ & 4.76 & 3.32 & 0.000 \\
\hline & Can often find some details which his classmates can't find & 4.62 & 3.52 & 0.004 \\
\hline & $\begin{array}{l}\text { Be a perfectionist, dealing object especially the preparations of } \\
\text { scientific experiment with perfect attitude, strive to the entirety } \\
\text { of experiment preparation. }\end{array}$ & 4.53 & 3.52 & 0.004 \\
\hline & $\begin{array}{l}\text { Will prepare and operate carefully and look for more effective } \\
\text { experimental method, even if the experiment steps are very } \\
\text { simple. }\end{array}$ & 4.74 & 3.23 & 0.000 \\
\hline & $\begin{array}{l}\text { When the experiment failed, always find the problem actively } \\
\text { through various channels, and actively prepare for the next } \\
\text { experiment until it succeed. }\end{array}$ & 4.85 & 3.26 & 0.000 \\
\hline & $\begin{array}{l}\text { Often take the initiative to give up rest time for the experiment } \\
\text { to collect experimental data, prepare experimental materials } \\
\text { and optimize experiment method during the university. }\end{array}$ & 4.92 & 3.46 & 0.000 \\
\hline & $\begin{array}{l}\text { Love medicine and be willing to struggle for the human health } \\
\text { of all beings. }\end{array}$ & 4.95 & 3.42 & 0.000 \\
\hline
\end{tabular}


According to the P-values in table 5, we can find that all the P-values of the cultural capital items are less than 0.05 , the significant difference passes through the statistical test, therefore, all the items are retained.

\section{Confirmatory Factor Analysis on the Measurement Index of Pharmaceutical Professional Students' Cultural Capital Measurement}

According to the result of item analysis and index revised result, programme the formal questionnaire of pharmaceutical professional students' cultural capital.

The formal questionnaire samples are still choosen from the employees in pharmaceutical enterprises, Guangzhou Baiyunshan Zhongyi Pharmaceutical Co. Ltd., Guangzhou Baiyunshan Qixing Pharmaceutical Co. Ltd., Guangzhou Pharmaceuticals Corporation, AstraZeneca pharmaceutical Co. Ltd., Pfizer pharmaceutical Co. Ltd., Chengdu Diao pharmaceutical Co. Ltd., Nanjing Sanhome pharmaceutical Co. Ltd., Beijing Youcare pharmaceutical group Co. Ltd., Lianyungang Hengrui Medicine Co. Ltd., Shanghai Municipal Food and Drug Administration, Food and Drug Administration of Shenzhen Municipality, JiangSu Food and Drug Administration, China Food and Drug Administration, Taizhou Institute for Food and Drug Control, Ningbo Institute for Drug Control. The research taken the network questionnaire, used the questionnaire star survey system to generate online questionnaire, processed cluster sampling via taking post as a unit, and excluded the objects extracted from the first questionnaire to avoid repetition, sent out 800 questionnaires, and taken back 742 questionnaires including 683 valid questionnaires, the effective rate was $92.05 \%$.

The reliability test. This study used SPSS19 to do reliability test for the cultural capital measurement scale of pharmaceutical professional students in the formal examination questionnaire, the results are shown in table 6 .

Table 6. Reliability statistics of the formal questionnaire scale

\begin{tabular}{ll}
\hline Scale & Cronbachs $\alpha$ based on standardization \\
\hline Cultural capital scale & 0.914 \\
\hline
\end{tabular}

From table 6, the (Cronbach) $\alpha$ of formal questionnaire is 0.914 . Therefore, the formal questionnaire scale has very good reliability.

Validity test. The first questionnaire of this research have ensured that the variable measurement has good content validity. As shown in table 7, each factor loading of measurement indicator is between 0.665 to 0.921 , which is greater than the standard value 0.50 , and it is outstanding at $\mathrm{P}<0.001$ level. The convergent validity of variables is between 0.880 to 0.917 , greater than the standard value 0.70 , so the measurement indicators in this questionnaire have good convergent validity.

Table 7. The analysis result of convergent validity

\begin{tabular}{lccc}
\hline Scale & Items & Factor loading & Convergent validity \\
\hline Cultural capital scale & 15 & $0.741 \sim 0.908$ & 0.917 \\
\hline
\end{tabular}

This study uses AMOS21 software to do confirmatory factor analysis on the measurement index of pharmaceutical professional students' cultural capital in the formal questionnaire, and names kindheartedness spirit as RA, scientific spirit as KX, and craftsman spirit as GJ respectively. All the label values of the measurement model are shown in table 8. 
Table 8 . The label values of cultural capital measurement model

\begin{tabular}{|c|c|c|}
\hline Cultural capital & Measurement items & $\begin{array}{l}\text { Label } \\
\text { values }\end{array}$ \\
\hline \multirow{4}{*}{$\begin{array}{l}\text { Kindheartedness } \\
\text { spirit } \\
\text { (RA) }\end{array}$} & $\begin{array}{l}\text { 1. Often take part in various social commonweal activities and youth volunteer } \\
\text { activities, such as nursing homes activities and community public welfare } \\
\text { activities. }\end{array}$ & RA1 \\
\hline & $\begin{array}{l}\text { 2. Be active to care about them, and give a hand to their life and study, when } \\
\text { their classmates are sick. }\end{array}$ & RA2 \\
\hline & $\begin{array}{l}\text { 3. Keep in touch with parents actively during the period of university, at least } \\
\text { twice a week. }\end{array}$ & RA3 \\
\hline & $\begin{array}{l}\text { 4. Take part in social activities actively such as blood and bone marrow } \\
\text { donation during the period of university. }\end{array}$ & RA4 \\
\hline \multirow{6}{*}{$\begin{array}{l}\text { Scientific spirit } \\
\qquad(\mathrm{KX})\end{array}$} & $\begin{array}{l}\text { 1. Often take part in all kinds of scientific research activities organized by } \\
\text { schools or teachers during the period of university, such as innovative } \\
\text { experiments, open experiments. }\end{array}$ & KX1 \\
\hline & $\begin{array}{l}\text { 2. Enrich their science knowledge actively from a variety of sources, such as } \\
\text { reading a lot of science and technology books except textbooks, participating in } \\
\text { the special science lectures in the university. }\end{array}$ & KX2 \\
\hline & $\begin{array}{l}\text { 3. Have done in-depth study exploration in university, such as mechanism of } \\
\text { drugs, polarity of drugs, and the unique function of medicinal herbs. }\end{array}$ & KX3 \\
\hline & $\begin{array}{l}\text { 4. Often attend science and technology competition activities school with his } \\
\text { classmates during the period of university. }\end{array}$ & KX4 \\
\hline & 5. Record the results and data faithfully every experiment during university & KX5 \\
\hline & 6. Can often find some details which his classmates can't find & KX6 \\
\hline \multirow{5}{*}{$\begin{array}{l}\text { Craftsman spirit } \\
\qquad(\mathrm{GJ})\end{array}$} & $\begin{array}{l}\text { 1. Be a perfectionist, dealing object especially the preparations of scientific } \\
\text { experiment with perfect attitude, strive to the entirety of experiment preparation. }\end{array}$ & GJ1 \\
\hline & $\begin{array}{l}\text { 2. Will prepare and operate carefully and look for more effective experimental } \\
\text { method, even if the experiment steps are very simple. }\end{array}$ & GJ2 \\
\hline & $\begin{array}{l}\text { 3. When the experiment failed, always find the problem actively through } \\
\text { various channels, and actively prepare for the next experiment until it succeed. }\end{array}$ & GJ3 \\
\hline & $\begin{array}{l}\text { 4. Often take the initiative to give up rest time for the experiment to collect } \\
\text { experimental data, prepare experimental materials and optimize experiment } \\
\text { method during the university. }\end{array}$ & GJ4 \\
\hline & 5. Love medicine and be willing to struggle for the human health of all beings. & GJ5 \\
\hline
\end{tabular}

Build a structure model of pharmaceutical professional students' cultural capital, combining with the formal questionnaire data and get the complete standard solution of the model parameter estimates, wich are shown in Figure 1. 


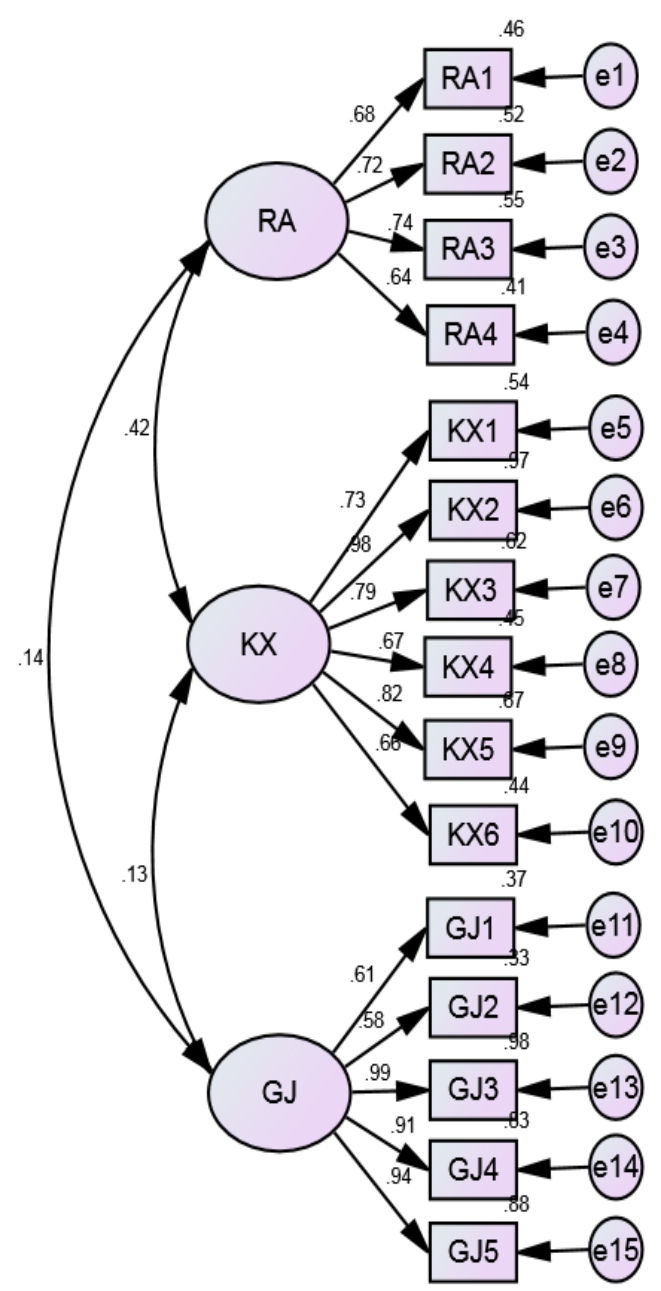

Figure 1. Structure model of pharmaceutical professional students' cultural capital

We can get to know from figure 1 , except one value is 0.58 , all the other standard factor loadings are of the 3 latent variables in 15 observations are above 0.6 , and there are 9 values which are not less than 0.72 . In the case of standardization, the multiple correlation coefficient between observation variable and latent variable is the square of factor loading. Therefore, there are 9 multiple correlation coefficients greater than 0.5 , that is to say, the corresponding latent variables can explain more than $60 \%$ of the observed variables, the interpretability of this model is strong.

The fitting index of confirmatory factor analysis in this study is shown in table 9.

Table 9. The fitting index of confirmatory factor analysis

\begin{tabular}{ccccccc}
\hline Model & CMIN & DF & CMIN/DF & CFI & TLI & RMR \\
\hline Default model & 117.972 & 87 & 1.356 & 0.950 & 0.919 & 0.012 \\
\hline
\end{tabular}

From table $9, \mathrm{CMIN} / \mathrm{DF}=1.356$, less than $3 ; \mathrm{CFI}=0.950, \mathrm{TLI}=0.950$, both are closed to $1 ; \mathrm{RMR}=0.012$, less than 0.05 . Therefore, the various fitting indexes show that the model's fitting effect is good.

\section{References}

Bao, R. J. (2011). The modern value of Confucian benevolence thought for the moral education of college students. Harbin Normal University.

Hu, J., \& Liao, Y. (2009). Introduction to the Confucian "benevolence" thought and the moral cultivation of college students. Management Observer, (17), 163-164. 
Li, X. L. (2016). Criticism and read on vulgarization and shallow understanding of craftsman spirit. Contemporary Vocational Education, (5), 4-5.

Lu, W., \& Xiang, Y. (1996).The position and role of spiritual civilization construction in medical education. Soft Science of Health, (5), 25-28.

Luo, Z. H., \& Pan, X. K. (2005). Practical Significance of Confucianists' Benevolent Spirit for Regulating College Students' Interpersonal Relationship. Journal of Guangxi Youth Leaders Co Hege, (1), 31-32, 51.

Wang, W. P., \& Ye, Z. (2015). The analysis on the support of cultural capital for university graduates' employment. Contemporary Youth Research, (2), 100-105.

$\mathrm{Xu}, \mathrm{Y}$. F. (2007). The practical significance of Confucian "benevolence" thinking for middle school moral education. Shandong Normal University.

Yi, X. F., \& Lin, H. Y. (2005). The empirical analysis of the contemporary college students' scientific spirit status quo. Journal of Zhuzhou Institute of Technology, (2), 23-26.

You, X. H., \& Guo, G. (2016). The quantitative evaluation and develop strategy of students' vocational values in applied colleges and universities - based on the questionnaire of 3 universities in SH city. Journal of Shanxi Institute of Economic Management, (4), 14-18, 21.

Zhang, X. L. (2010). On the Evaluation Scale of Innovative Behaviors for S\&T Talents. Chinese Public Administration, (7), 107-111.

\section{Copyrights}

Copyright for this article is retained by the author(s), with first publication rights granted to the journal.

This is an open-access article distributed under the terms and conditions of the Creative Commons Attribution license (http://creativecommons.org/licenses/by/4.0/). 